\title{
Profile of Female Patients at a Sexology Ambulatory in the Brazilian Public Health System
}

\author{
Janete Vettorazzi 1,2,3,4* , Edimárlei Gonsales Valério1,2,3,4, Bruno Florentino Goldani4,5, \\ Thomas Lucas Toledo de Souza ${ }^{4,5}$, Paula Capra ${ }^{4,5}$, Bruno Ribeiro Bossardi ${ }^{4,5}$, \\ Mariana Hollmann Scheffler ${ }^{4,5}$, Fernanda Santos Grossi1,4, Luciana Segat ${ }^{1,4}$
}

\author{
${ }^{1}$ Postgraduate Program in Health Sciences: Gynecology and Obstetrics, Universidade Federal do Rio Grande do Sul (UFRGS), \\ Porto Alegre, Brasil \\ ${ }^{2}$ Department of Gynecology and Obstetrics, Faculty of Medicine (FAMED), Universidade Federal do Rio Grande do Sul, Porto \\ Alegre, Brasil \\ ${ }^{3}$ Service of Obstetrics and Gynecology, Hospital de Clínicas de Porto Alegre, Porto Alegre, Brasil \\ ${ }^{4}$ Nucleus of Studies and Research in Sexuality of Rio Grande do Sul (NEPESEX), CNPq, Caxias do Sul, Brasil \\ ${ }^{5}$ Faculty of Medicine (FAMED), Universidade Federal do Rio Grande do Sul, Porto Alegre, Brasil \\ Email: *jvettorazzi@hcpa.edu.br
}

\begin{abstract}
How to cite this paper: Vettorazzi, J., Valério, E.G., Goldani, B.F., de Souza, T.L.T., Capra, P., Bossardi, B.R., Scheffler, M.H., Grossi, F.S. and Segat, L. (2018) Profile of Female Patients at a Sexology Ambulatory in the Brazilian Public Health System. Open Journal of Obstetrics and Gynecology, 8, 1185-1197. https://doi.org/10.4236/ojog.2018.812120
\end{abstract}

Received: September 3, 2018

Accepted: October 21, 2018

Published: October 24, 2018

Copyright ( 92018 by authors and Scientific Research Publishing Inc. This work is licensed under the Creative Commons Attribution International License (CC BY 4.0).

http://creativecommons.org/licenses/by/4.0/

cC) (i) Open Access

\begin{abstract}
Introduction: Sexual problems are fairly common, and sexuality is an important parameter of health and quality of life. However, only a few centers in Brazil have ambulatories specialized in sexual dysfunction. This study was conducted in a service that is a state reference for these pathologies. Methods: This study was conducted at the human sexuality ambulatory of a large public hospital in southern Brazil. It was a cross-sectional descriptive study with women attending at the first medical visit to the ambulatory of human sexuality in a period of four years. Female Sexual Function Index (FSFI) questionnaires with both qualitative and quantitative questions were applied in all first medical visits to the ambulatory. Results: The 153 women attending had a mean age of $40.9( \pm 12.9)$ years. The most frequent complaint was "lack of desire" (56.8\%), followed by pain in intercourse (25.4\%) and lack of pleasure or inability to achieve orgasm (12.4\%). The prevalence of sexual dysfunction (FSFI cut-off score $<26.5$ ) was $74.5 \%$. The patient's age, the age of the partner, and the length of the relationship with the partner had a significant correlation with a lower FSFI score. There was an inverse correlation between the length of the relationship and the FSFI score. The self-attributed score for satisfaction with sexual life had a significant correlation with the FSFI total score $(r=0.708, p<0.01)$. Conclusion: We conclude that women who seek care in sexuality are in the perimenopausal period and that factors such as the number of children, age of menopause and length of the relation-
\end{abstract}


ship have a negative influence on sexuality. The score for the self-assessment of sexuality could serve as an initial screening for sexual dysfunction, since it is quick and easy to apply in routine medical visits. However, more studies are required to compare the FSFI and this score.

\section{Keywords}

Sexuality, Sexual Dysfunction, Public Health

\section{Introduction}

According to the World Health Organization (WHO), sexuality is an important parameter of health and quality of life. Studies that evaluate the incidence and prevalence of sexual dysfunction (SD) in women are scarce and present many methodological differences, making it difficult to obtain real data. The proper interpretation of the questionnaires may justify this difficulty [1].

Most studies find a high prevalence of sexual dysfunction among women. This makes SD to be considered a public health problem, which justifies the appropriate approach and treatment of this condition, improving the quality of life of men and women [2]. Studies performed [3] [4] among Brazilian women found a prevalence of some sexual difficulty above $80 \%$, with an average of $30 \%$ to $50 \%$ of women presenting some SD. The main sexual complaints of Brazilian women are related to the difficulties of arousal (27\%), orgasm difficulty (26\%), dyspareunia (18\%) and hypoactive sexual desire (8\%).

The percentages may vary depending on socio-economic factors, age group, and partner's sexual function, among other conditions [5] [6] [7].

The American College of Obstetricians and Gynecologists (ACOG) [8] [9], defines that gynecologists and obstetricians play a fundamental role in the evaluation of sexual function, with the function of listening to and counseling patients, always considering socio-cultural variations in sexual practices. Despite the high prevalence of SD and the clinical relevance of the topic, sexuality is still poorly discussed in medical care [5]. Fewer than half of patients talk about their sexual complaints with their doctor [10]. In the Brazilian context, there are few centers specialized in the treatment of SD, especially in public healthcare. The state of Rio Grande do Sul has 11.2 million inhabitants, and there are only five public health outpatient clinics for female SD.

This study was conducted in a sexuality outpatient clinic in a reference center in southern Brazil. This ambulatory was founded 16 years ago and offers between 15 and 20 weekly medical visits to women with SD in the public health system. The main objective of this study is to outline the profile of women who seek medical care for SD in the public health system.

\section{Methods}

We conducted a cross-sectional descriptive study with 153 women attended at 
the first medical visit to the ambulatory of human sexuality of the between August 2012 and August 2016. Patients were excluded if they did not complete the questionnaires $(\mathrm{n}=11)$ or was biologically male $(\mathrm{n}=1)$.

The women referred to the sexuality clinic answered an initial questionnaire about the reason for the consultation, data on age, marital status, education, number of children, and other socio-demographic characteristics. We also evaluated he Female Sexual Function Index (FSFI) questionnaire score, which is applied routinely at the first medical visit. This instrument has been translated and validated for use in Brazilian Portuguese [11]. A score less or equal to 26.5 is considered positive for female SD. Over the course of the study (from the year 2014), the question "How would you rate your sex life on a scale of 0 to 10 ?" (10 being very satisfied and 0 for complete dissatisfaction) was also added to the questionnaires.

Data analysis was performed using descriptive statistics (mean, standard deviation, minimum, maximum, frequencies, and percentages) and Pearson correlation coefficient $(r)$ for the measurement of covariance. SPSS software version 18.0 was used for the analysis.

\section{Results}

In a four-year period, we analyzed 153 women in their first visit to an ambulatory specialized in human sexuality at a public university hospital in the south of Brazil, they were referred through the public health system. The patients had a mean age of $40.9( \pm 12.9)$ years, ranging from 18 to 68 years. Regarding education, $55.5 \%$ had completed primary education or less (8 years or less of study), $34 \%$ had completed secondary education (11 years of study), and only $4.5 \%$ had completed tertiary education (bachelor's or master's degree) (Table 1).

Table 1. Profile of the women who consulted in a public Brazilian sexuality ambulatory $(\mathrm{n}=153)$.

\begin{tabular}{ccc}
\hline & Number (SD) & $\%$ \\
\hline Age (years) & & \\
Mean (SD) & $40.9(12.9)$ & \\
Education $^{1}$ & & 55.5 \\
Primary or less & 85 & 34 \\
Secondary & 53 & 4.5 \\
Tertiary (Higher) & 7 & \\
Main complaint & & 25.4 \\
Pain during sexual intercourse & 39 & 12.4 \\
Lack of pleasure/orgasm & 19 & 56.8 \\
Lack of desire & 87 & 1.9 \\
Impossibility of penetration & 3 & 3.2 \\
Others & 5 & \\
Steady partner & & \\
\hline
\end{tabular}




\begin{tabular}{ccc} 
Continued & & \\
\hline Yes & 143 & 93.4 \\
No & 10 & 6.6 \\
Partner's age (years) & $43.7(14.1)$ & \\
Mean (SD) & & \\
Relationship length (years) & $16.2(13.0)$ & \\
Mean (SD) & & 24.8 \\
Number of children ${ }^{2}$ & 38 & 19.6 \\
0 & 30 & 27.4 \\
1 & 42 & 24.8 \\
2 & 38 & \\
$\geq 3$ & & \\
Youngest child's age (years) & $14.9(9.6)$ &
\end{tabular}

${ }^{1} \mathrm{n}$ of non-reported $=8(5.2 \%) ;{ }^{2} \mathrm{n}$ of non-reported $=5(3.2 \%)$.

The vast majority of women (93.4\%) had a fixed partner, with an average relationship time of $16.2( \pm 13.0)$ years. The partners had a mean age of $43.7( \pm 14.1)$ years, being 2.8 years older than the patients. Approximately one quarter of patients $(24.8 \%)$ had no children. Among the others, $19.6 \%$ had only one child, $27.4 \%$ had two children, and $24.8 \%$ had three or more children. The mean age of the youngest child was $14.9( \pm 9.6)$ years (Table 1$)$.

The main complaint reported by the patients at the first visit was analyzed and classified into four main categories. The most frequent complaint was "lack of desire" (56.8\%), followed by pain in the intercourse $(25.4 \%)$ and lack of pleasure or lack of orgasm (12.4\%). A small group (1.9\%) still reported "impossibility of vaginal penetration", and $3.2 \%$ of the patients presented diverse complaints such as related to the partner or their sexual performance (Table 1). The main complaint at the first medical visit varied according to the age of the patients. Up to the age of 25 , the main complaint was pain during sexual intercourse $(48.1 \%)$, whereas the lack of desire was the main complaint in all other age groups: $54.8 \%$ from 26 to $40,66.2 \%$ from 40 at 55, and $73.7 \%$ after 56 (Figure 1).

The prevalence of SD, defined by the FSFI as a total score lower than 26.5, was $74.5 \%$. Regarding the scores obtained in the smaller domains, the desire category had the lowest score $(2.3 \pm 1.3)$, followed by arousal $(2.5 \pm 1.5)$ and orgasm $(2.5$ \pm 1.7). Satisfaction, pain, and lubrication scored $2.9 \pm 1.4,3.1 \pm 1.7$, and $3.2 \pm$ 1.8 , respectively (Table 2 ).

The socio-demographic factors that were significantly correlated with a lower total FSFI score were age, partner's age, relationship length, and number of children (Table 3 ), and the factor with the strongest negative correlation was the age of the partner $(\mathrm{r}=-0.315)$.

Among the 69 patients asked about the score they would give to their sexual life on a 0 to 10 scale, $25(16.3 \%)$ reported a score of 0 , and $15(9.8 \%)$ reported a 


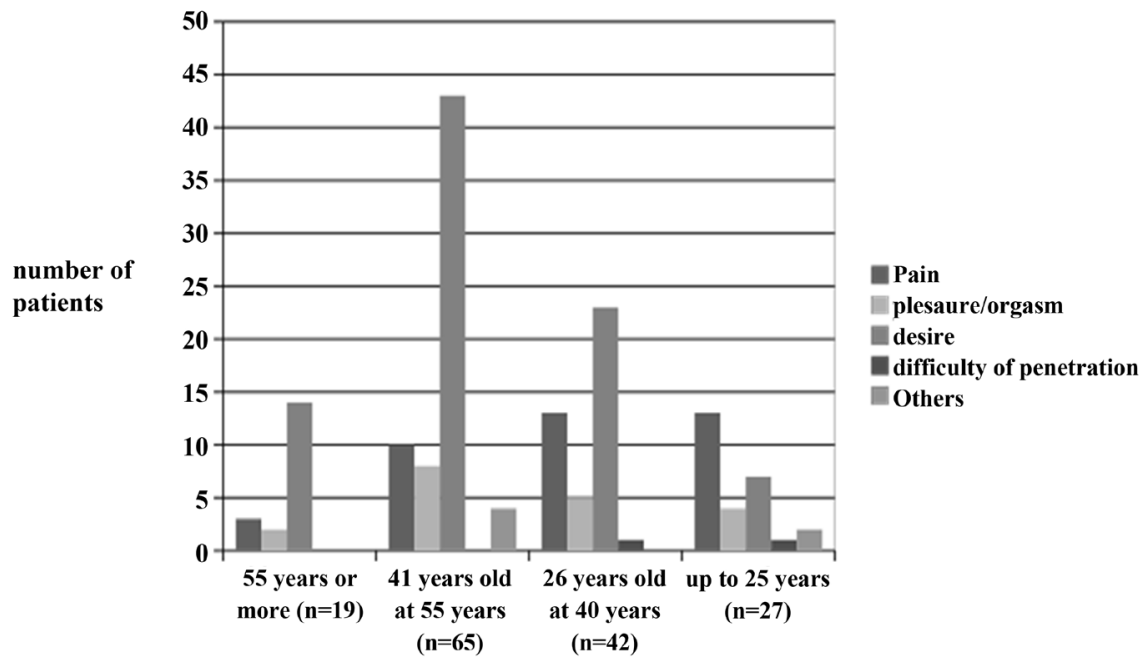

Figure 1. Main complaint according to age group in women at first medical visit in a public Brazilian sexuality ambulatory.

Table 2. FSFI sexual function domain scores of women at first medical visit in a public Brazilian sexuality ambulatory $(\mathrm{n}=128)^{*}$.

\begin{tabular}{cc}
\hline Domain & Score (SD) \\
\hline Desire & $2.3(1.3)$ \\
Arousal & $2.5(1.5)$ \\
Lubrication & $3.2(1.8)$ \\
Orgasm & $2.5(1.7)$ \\
Satisfaction & $2.9(1.4)$ \\
Pain & $3.1(1.7)$ \\
Total & $16.7(7.4)$ \\
\hline
\end{tabular}

$\star 25$ (15.3\%) losses due to incomplete FSFI filling. FSFI: Female Sexual Function Index.

Table 3. Correlation ${ }^{1}$ among FSFI total score (TS), FSFI domain scores, and socio-demographic factors in women at first medical visit in a public Brazilian sexuality ambulatory.

\begin{tabular}{cccccccc}
\hline Factor & TS & Desire & Arousal & Lubrication & Orgasm & Satisfaction & Pain \\
\hline Age (years) & $-0.272^{* *}$ & $-0.285^{* *}$ & $-0.273^{* *}$ & $-0.222^{* *}$ & -0.120 & -0.164 & -0.063 \\
$\begin{array}{c}\text { Education } \\
\text { study years) }\end{array}$ & 0.114 & 0.067 & $0.167^{*}$ & 0.128 & 0.156 & 0.139 & -0.039 \\
$\begin{array}{c}\text { Partner's age } \\
\text { (years) }\end{array}$ & $-0.315^{* *}$ & $-0.279^{* *}$ & $-0.308^{* *}$ & $-0.225^{*}$ & $-0.229^{*}$ & -0.183 & -0.103 \\
$\begin{array}{c}\text { Relationship } \\
\text { length (years) }\end{array}$ & $-0.230^{*}$ & $-0.249^{* *}$ & $-0.274^{* *}$ & $-0.184^{*}$ & -0.055 & -0.138 & 0.018 \\
$\begin{array}{c}\text { Number of } \\
\text { children }\end{array}$ & $-0.232^{* *}$ & $-0.173^{*}$ & $-0.213^{*}$ & -0.144 & -0.109 & $-0.315^{* *}$ & 0.017 \\
$\begin{array}{c}\text { Youngest child's } \\
\text { age (years) }\end{array}$ & -0.189 & -0.062 & -0.149 & -0.175 & -0.079 & -0.079 & -0.066 \\
\hline
\end{tabular}

${ }^{1}$ Defined by the Pearson correlation coefficient $(\mathrm{r})$; ${ }^{*}$ Significant at the $\mathrm{p}<0.05$ level; ${ }^{*}$ Significant at the $\mathrm{p}<$ 0.01 level. FSFI: Female Sexual Function Index. 
score of 5 (Figure 2). The self-attributed score for satisfaction with the current sexual life demonstrated a strong and significant correlation with the FSFI total score $(\mathrm{r}=0.708, \mathrm{p}<0.01)$.

\section{Discussion}

Despite the age variation among the patients who seek care for SD, we observed that the majority are in the perimenopausal period. Similar data were found in a study (Uchoa, 2014) conducted in the public health system in northeastern Brazil, among female patients with a mean age of 49 years, in which $67 \%$ had SD assessed through the FSFI [12]. Hence, the mean age, 40 years, corroborates the most frequent main complaint to be a lack of desire (56.8\%), which increases with aging in our sample. Analyzing the age of the patients and the FSFI score, we found an inverse $(<-0.3)$ and significant $(\mathrm{p}<0.01)$ correlation, meaning that an increase of age is related to worsening of sexual function. Regarding this correlation, the FSFI categories responsible for the strongest and most significant inverse association were desire, arousal, and lubrication. This result is expected, since with aging physical and hormonal changes occur in the life cycle of women, as well as changes related to general health and intimate relationships that may contribute to the onset of SD.

According to an Australian study, decrease in desire seems to be related to the presence of a steady partner and worsens according to the time length of the relationship. Stable and long-lasting relationships can negatively interfere with female spontaneous desire [13]. In our sample, 93\% of the women had a fixed partner, and the average time of the relationship was 16 years, a factor that could have contributed to one of the main complaints-a lack of desire-since there was an inverse correlation between the years of the relationship and the FSFI score. We also found an inverse correlation between the number of children and the FSFI score. It is important to notice that the number of children is expected to increase according to the relationship length, and thus those two correlations may be closely related. However, we did not find a correlation between the age

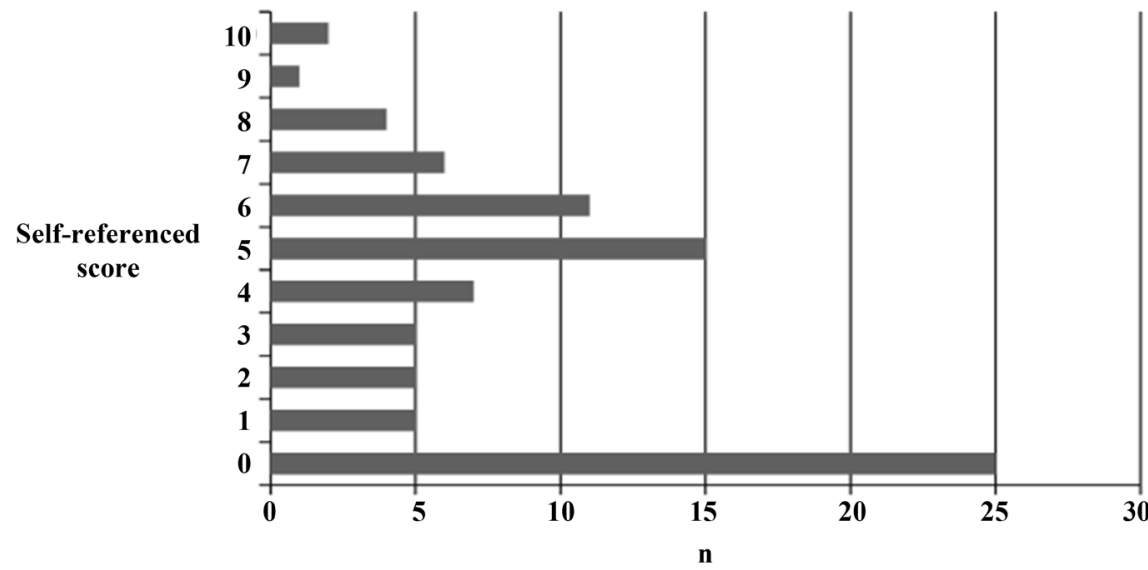

Figure 2. Self-referenced score for sexuality satisfaction factors in women at first medical visit in a public Brazilian sexuality ambulatory $(n=69)$. 
of the youngest child and the FSFI score, which implies that motherhood itself has an impact on the sexual life of the patients, regardless of the age of the children.

In this study, the sexual function of the partner was not evaluated, which is one of the factors that can influence women's satisfaction with their sexuality [14]. However, we found an inverse correlation between the partner's age and the FSFI score. Analysing by category, the strongest correlations with statistical significance were arousal, desire, orgasm, and lubrication. These data reinforce the need for greater participation of the partners in the medical visits, since most of the complaints can be helped with proper instruction to the couple. In addition, the presence of the partner at a medical visit can allow for screening and referral to a specialized professional if necessary and if the partner accepts.

Regarding women's self-reported score for their sexuality on the first medical visit, the most reported score was 0 (16.3\%), followed by 5 (9.8\%). These data provide a quantitative parameter for assessing the degree that SD affects the sexual life of the patient. In addition, the self-attributed score and FSFI score showed a strong and significant correlation. In this context, the self-attributed score for sexuality could serve as an initial screening for SD, since it is quick and easy to apply in routine medical visits. Further studies are needed to access this potential tool, as well as to evaluate the improvement of this parameter after treatment.

The cause of SD is very likely multifactorial [15]. Several studies have found that education might influence SD. Some studies have shown a correlation between lower education and SD, while others have shown that women with higher education have a higher prevalence of SD. There are even some studies that did not find a statistically significant correlation between education and SD [13]. In our sample, no significant correlation was found between education and the FSFI score, which leads us to raise the hypothesis that education does not have an impact on the development of SD.

Considering that this is a retrospective observational study, our findings should serve as a basis for future studies. One of the limitations of this study is the low level of education of the patients, which might influence the correct understanding and fulfillment of the FSFI.

\section{Conclusions}

Women who seek sexual care are usually in the perimenopausal period. Their sexual lives could be influenced negatively by many factors, such as the number of children, age of menopause, or length of relationship. We can perform an initial screening for SD by using the self-attributed score, since it is quick and easy to apply in routine medical visits. However, we need more studies to compare this score to the FSFI.

Considering that health professionals should treat their patients holistically rather than treat a single disease, our study is of paramount importance for the 
advancement of the study of sexology. Our findings may help to improve the healthcare of patients with SD, providing information and better preparation to healthcare providers in the approach to questions related to sexuality. In addition, the understanding of patients' profile may help targeting new studies in the area of sexuality and SD, as well as provide data for other research groups to develop comparative studies. We encourage future studies to be performed in order to better understand SD in other public and private health services.

\section{Conflicts of Interest}

The authors declare no conflicts of interest regarding the publication of this paper.

\section{References}

[1] McCabe, M.P., Sharlip, I.D., Lewis, R., Atalla, E., Balon, R., Fischer, A.D., Laumann, E., Lee, S.W. and Segraves, R.T. (2016) Incidence E prevalence of Sexual Dysfunction in Women and Men: A Consensus Statement from the Fourth International Consultation on Sexual Medicine. The Journal of Sexual Medicine, 13, 144-152. https://doi.org/10.1016/j.jsxm.2015.12.034

[2] World Health Organization (WHO), Department of Reproductive Health and Research (2006) Defining Sexual Health. Report of a Technical Consultation on Sexual Health, 28-31 January 2002, WHO, Geneva.

[3] Abdo, C.H.N. (2002) Perfil sexual da populaçäo brasileira: resultado do Estudo do Comportamento Sexual (ECOS) do Brasileiro. Revista Brasileira de Medicina, 59, 250-257.

[4] Abdo, C.H.N., Moreira, J.E.D. and Fittipaldi, J.A.S. (2000) Estudo do comportamento sexual no Brasil-ECOS. Revista Brasileira de Medicina, 57, 1329-1335.

[5] Prado, D.S., Mota, V.P.L.P. and Lima, T.I.A. (2010) Prevalência de disfunção sexual em dois grupos de mulheres de diferentes níveis socioeconômicos. Revista Brasileira de Ginecologia e Obstetrícia, 32, 139-143. https://doi.org/10.1590/S0100-72032010000300007

[6] Wolpe, R.E., Zomkowski, K., Silva, F.P., Queiroz, A.P. and Sperandio, F.F. (2017) Prevalence of Female Sexual Dysfunction in Brazil: A Systematic Review. European Journal of Obstetrics \& Gynecology and Reproductive Biology, 211, 26-32. https://doi.org/10.1016/j.ejogrb.2017.01.018

[7] Abdo, C.H. (2004) Estudo da vida sexual do brasileiro. Bragantini, São Paulo.

[8] Sexual Health (2018) ACOG 2017. https://www.acog.org/Resources-And-Publications/Committee-Opinions/Committ ee-on-Gynecologic-Practice/Sexual-Health

[9] Committee on Gynecologic Practice (2017) Committee Opinion No 706, Sexual Health. Obstetrics \& Gynecology, 130, e42-e47. https://doi.org/10.1097/AOG.0000000000002161

[10] Parish, S.J. and Hahn, S.R. (2016) Hypoactive Sexual Desire Disorder: A Review of Epidemiology, Biopsychology, Diagnosis, and Treatment. Sexual Medicine Reviews, 4, 103-120. https://doi.org/10.1016/j.sxmr.2015.11.009

[11] Hentschel, H., Alberton, D.L., Capp, E., José Roberto Goldim, J.R. and Passos, E.P. (2007) Validação do female sexual function index (FSFI) para uso em língua portuguesa. Revista do Hospital de Clínicas de Porto Alegre e Faculdade de Medicina da 
Universidade Federal do Rio Grande do Sul, 27, 10-14.

[12] Cabral, P.U., Canário, A.C., Spyrides, M.H., Uchôa, S.A., Eleutério Júnior, J., Giraldo, P.C. and Gonçalves, A.K. (1992) Physical Activity and Sexual Function in Middle-Aged Women. Revista da Associação Médica Brasileira, 60, 47-52. https://doi.org/10.1590/1806-9282.60.01.011

[13] Hayes, R.D., Dennerstein, L., Bennett, C.M., Sidat, M., Gurrin, L.C. and Fairley, C.K. (2008) Risk Factors for Female Sexual Dysfunction in the General Population: Exploring Factors Associated with Low Sexual Function and Sexual Distress. The Journal of Sexual Medicine, 5, 1681-1693. https://doi.org/10.1111/j.1743-6109.2008.00838.x

[14] Lett, C., Valadares, A.L.R., Baccaro, L.F., Pedro, A.O., Filho, J.L., Lima, M., et al. (2017) Is the Age at Menopause a Cause of Sexual Dysfunction? A Brazilian Population-Based Study. Menopause, 25, 70-76.

[15] Ferreira, A.L.C.G., Souza, A.I.D., Ardisson, C.L. and Katz, L. (2007) Disfunções sexuais femininas. Femina, 35, 689-695. 


\section{Appendix}

\section{Sexuality Questionnaire INICIAL}

HCPA Sexuality Ambulatory

Professors: Janete Vettorazzi/Edimárlei Gonsales Valério

Date: Medical record: Cor

Routing ( ) BHU ( ) HCPA ( ) Interior Moment: ( ) First appointment ( ) Final

Fixed partner: ( ) YES ( ) NO ; Number of sexual partners in life:

Time with the current partner

Sexuality questionnaire-FSFI//HCPA ambulatory//Medical record:

1) In the past 4 weeks, how often (how many times) have you felt desire or sexual interest?

$5=$ almost always

$4=$ most times (more than half the time)

$3=$ sometimes (about half the time)

$2=\mathrm{a}$ few times (less than a half the time)

$1=$ almost never or never

2) In the past 4 weeks, how do you rate your degree of desire or sexual interest?

$$
\begin{aligned}
& 5=\text { very high } \\
& 4=\text { high } \\
& 3=\text { moderate } \\
& 2=\text { low } \\
& 1=\text { very low or none }
\end{aligned}
$$

3) In the past 4 weeks, how often (how many times) have you felt sexual arousal during sexual activity or act?

$$
\begin{aligned}
& 0=\text { no sexual activity } \\
& 1=\text { almost never or never } \\
& 2=\text { a few times (less than a half the time) } \\
& 3=\text { sometimes (about half the time) } \\
& 4=\text { most times (more than half the time) } \\
& 5=\text { almost always }
\end{aligned}
$$

4) In the past 4 weeks, how do you rate your degree of sexual arousal during sexual activity or act?

$$
\begin{aligned}
& 0=\text { no sexual activity } \\
& 1=\text { very low or none } \\
& 2=\text { low } \\
& 3=\text { moderate } \\
& 4=\text { high }
\end{aligned}
$$


$5=$ very high

5) In the past 4 weeks, how do you rate your degree of safety to be sexually aroused during sexual activity or act?

$0=$ no sexual activity

$1=$ very low or no safety

2 = low safety

$3=$ moderate safety

$4=$ high safety

$5=$ very high safety

6) In the past 4 weeks, how often (how many times) have you been satisfied with your sexual arousal during sexual activity or act?

$0=$ no sexual activity

$1=$ almost never

$2=\mathrm{a}$ few times (less than a half the time)

$3=$ sometimes (about half the time)

$4=$ most times (more than half the time)

$5=$ almost always or always

7) In the past 4 weeks, how often (how many times) have you had vaginal lubrication ("wet vagina") during sexual activity or act?

$0=$ no sexual activity

$1=$ almost never or never

$2=\mathrm{a}$ few times (less than a half the time)

3 = sometimes (about half the time)

$4=$ most times (more than half the time)

$5=$ almost always or always

8) In the past 4 weeks, how do you evaluate your difficulty to have vaginal lubrication ("wet vagina") during sexual activity or act?

$0=$ no sexual activity

$1=$ extremely hard or impossible

$2=$ very hard

$3=$ hard

$4=$ slightly hard

$5=$ not hard at all

9) In the past 4 weeks, how often (how many times) have you kept your vaginal lubrication ("wet vagina") until the end of sexual activity or act?

$0=$ no sexual activity

$1=$ almost never or never

$2=\mathrm{a}$ few times (less than a half the time)

$3=$ sometimes (about half the time)

$4=$ most times (more than half the time)

$5=$ almost always or always

10) In the past 4 weeks, how hard it was to keep the vaginal lubrication ("wet vagina") until the end of sexual activity or act? 
$0=$ no sexual activity

$1=$ extremely hard or impossible

$2=$ very hard

$3=$ hard

$4=$ slightly hard

$5=$ not hard at all

11) In the past 4 weeks, when you had sexual stimuli or act, how often have you achieved orgasm (climax)?

$0=$ no sexual activity

$1=$ almost never or never

$2=\mathrm{a}$ few times (less than a half the time)

$3=$ sometimes (about half the time)

$4=$ most times (more than half the time)

$5=$ almost always or always

12) In the past 4 weeks, when you had sexual stimuli or act, how hard it was to achieve orgasm (climax)?

$0=$ no sexual activity

$1=$ extremely hard or impossible

$2=$ very hard

$3=$ hard

$4=$ slightly hard

$5=$ not hard at all

13) In the past 4 weeks, how satisfied you got with your capacity to achieve orgasm (climax during sexual activity or act?

$0=$ no sexual activity

$1=$ very dissatisfied

$2=$ moderately dissatisfied

$3=$ almost equally satisfied and dissatisfied

$4=$ moderately dissatisfied

$5=$ very satisfied

14) In the past 4 weeks, how satisfied you were with the emotional proximity between you and your partner during sexual activity?

$0=$ no sexual activity

$1=$ very dissatisfied

$2=$ moderately dissatisfied

$3=$ almost equally satisfied and dissatisfied

$4=$ moderately dissatisfied

$5=$ very satisfied

15) In the past 4 weeks, how satisfied you were with the sexual relationship between you and your partner?

$0=$ no sexual activity

$1=$ very dissatisfied

$2=$ moderately dissatisfied 
3 = almost equally satisfied and dissatisfied

$4=$ moderately dissatisfied

$5=$ very satisfied

16) In the past 4 weeks, how satisfied you were with your sexual life in the whole?

$1=$ very dissatisfied

$2=$ moderately dissatisfied

3 = almost equally satisfied and dissatisfied

$4=$ moderately dissatisfied

$5=$ very satisfied

17) In the past 4 weeks, how often (how many times) have you felt pain or discomfort during penetration?

$0=$ haven't tried to have relations

$1=$ almost Always or always

$2=$ most times (more than half the time)

3 = sometimes (about half the time)

$4=\mathrm{a}$ few times (less than a half the time)

$5=$ almost never or never

18) In the past 4 weeks, how often (how many times) have you felt pain or discomfort after vaginal penetration?

$0=$ haven't tried to have relations

$1=$ almost Always or always

$2=$ most times (more than half the time)

3 = sometimes (about half the time)

$4=\mathrm{a}$ few times (less than a half the time)

$5=$ almost never or never

19) In the past 4 weeks, how would you rate your grade of pain or discomfort during or after vaginal penetration?

$0=$ haven't tried to have relations

$1=$ very high

2 = high

$3=$ moderate

$4=$ low

$5=$ very low or none 